Document downloaded from:

http://hdl.handle.net/10251/146188

This paper must be cited as:

Gaviria, X.; Borrachero Rosado, MV.; Paya Bernabeu, JJ.; Monzó Balbuena, JM.; Tobón, J. (04-2). Mineralogical evolution of cement pastes at early ages based on thermogravimetric analysis (TGA). Journal of Thermal Analysis and Calorimetry. 132(1):39-46.

https://doi.org/10.1007/s10973-017-6905-0

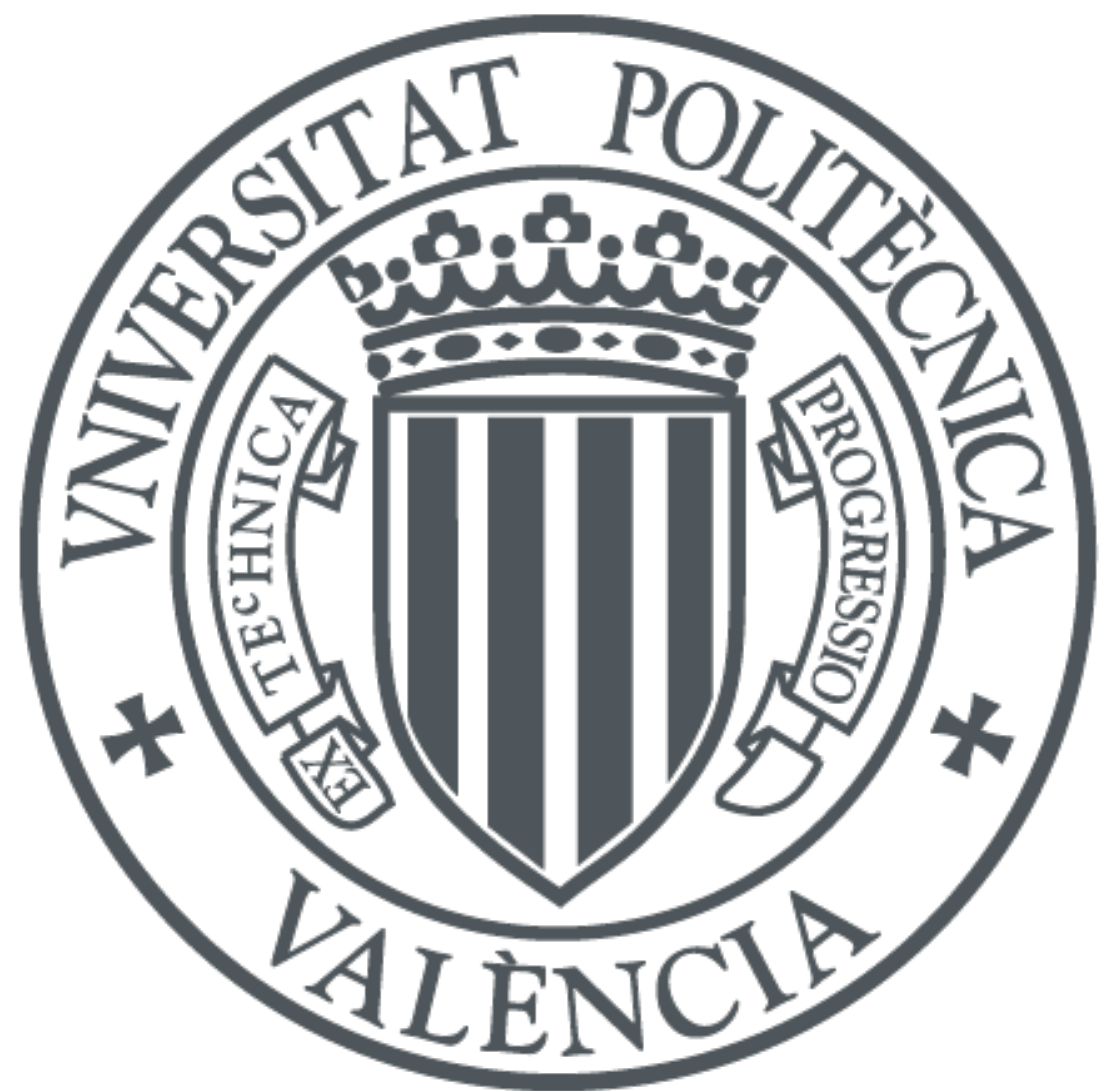

The final publication is available at

https://doi.org/10.1007/s10973-017-6905-0

Copyright Springer-Verlag

Additional Information 


\title{
MINERALOGICAL EVOLUTION OF CEMENT PASTES AT EARLY AGES BASED ON THERMOGRAVIMETRIC ANALYSIS (TGA)
}

X. Gaviria, M.V. Borrachero, J. Payá, J.M.Monzó, J.I. Tobón,

X. Gaviria, J. I. Tobón

Grupo Del Cemento y Materiales de Construcción, Universidad Nacional de Colombia, Medellín, e-mail: xgaviri@unal.edu.co

M. V. Borrachero, J. Paya, J. M. Monzó

Instituto de Ciencia y Tecnología del Hormigón (ICITECH), Universidad Politécnica de Valencia, Valencia, Spain

\begin{abstract}
Ordinary TGA and high-resolution TGA tests were carried out on three different Portland cements to study the phases present during the first day of hydration. Tests were run at $1,6,12$, and 24 hours of hydration, in order to determine the phases at these ages. High-resolution TGA tests were used to separate decompositions presented in the $100-200{ }^{\circ} \mathrm{C}$ interval. The non-evaporable water determined by TGA was used to determine hydration degree for the different ages. The effect of particle size distribution (PSD) on mineralogical evolution was established, as well as the addition of calcite as mineralogical filler. Finer PSD and calcite addition accelerates the hydration process, increasing the hydration degree on the first day of reaction between water and cement. According to high-resolution TGA results it was demonstrated that ettringite was the only decomposed phase in the $100-200^{\circ} \mathrm{C}$ interval during the first 6 hours of hydration for all studied cements. C-S-H phase starts to appear in all cements after 12 hours of hydration.
\end{abstract}

Key words: TGA, high-resolution TGA, hydration degree, cement pastes

1. Introduction

At early ages, right after mixing cement and water, cement paste has the lowest capacity to support loads, but it has the greatest possibility to generate internal stresses, which are the origin of cracks [1-3]. Cracks formed during this early age are internal and microscopic, but they can open and grow, thus generating big problems with time [4].

Early cracks are generated during the first 24 hours and they are usually associated with volume changes at early ages [5-7]. Volume changes at this time are the result of complex physicochemical phenomena. These phenomena are related to hydration reactions between cement and water and the progressive hardening of the material $[6,8]$. Hydration products volume is less than the one of the original materials, including mixing water, which produces shrinkage. This shrinkage is associated to mineralogical evolution and brings important performance implications at early ages of materials related to cement $[2,6,9]$. That is why it is important to study the mineralogical evolution during the first hours of hydration and thermogravimetric analysis (TGA) is an adequate technique to study this phenomenon.

The thermogravimetric analysis (TGA) measures mass changes in a material as a function of time at a determinate temperature (isothermal mode) or at a temperature range with a fixed heating rate [10, 11]. Usually, the mass variation is a loss due to chemical reactions during heating. Volatile compounds are produced during the heating, being the produced reactions of different types: combustion/oxidation, dehydration and decomposition $[12,13]$. The mass loss curve obtained in a TGA test and its first derivate curve (derivative thermogravimetry, DTG) are useful to identify the phases and to quantify some of the phases in a sample of clay, plaster, gypsum and cements, among others. [13-15].

TGA is a useful technique to study physical and chemical phenomena associated to formation of cementhydrated phases $[13,16]$. The problem of this technique for cementitious materials is that the decomposition temperature of different phases is too close, generating peaks overlapping in the DTG curve [15]. In cement pastes, it is usual to find overlapping of ettringite, C-S-H and gypsum DTG peaks. The decomposition of 
these phases is in the $100-180{ }^{\circ} \mathrm{C}$ range and the constant heating of the test impedes the differentiation of each peak. This is showed in the DTG curve as shoulders or widening peaks in this temperature range. The phases cannot be identified in this zone of the thermogram and quantification of phases is a difficult task [15, $17,18]$. Portlandite is the hydrated phase of cement that can be quantify in an accurate way using TGA technique. The decomposition temperature of portlandite is far from other phases (around $500{ }^{\circ} \mathrm{C}$ ) $[13,16]$.

It has been noticed that adaptation of the heating rate is essential for investigation on thermal decomposition reactions. This procedure also helps to separate overlapping slow dehydration steps and allows for quasiisothermal conditions during the main reactions $[11,12,14,15,17,19]$. Some TGA equipments count with the high resolution (Hi-ResTM) or maximum resolution (MaxResTM) module that reduces the heating rate when a mass variation of the sample is detected [13]. Running a whole TGA test using low heating rate, could be another way to avoid peak overlapping, but it would be a time consuming and, therefore, very expensive test $[15,17]$.

With the high-resolution module, heating rate varies in a continuous and dynamic way to increase resolution, according to mass loss rate. It means that the heating rate will be reduced in those points where a significant mass change is detected and it will be increase when no mass change is detected [14]. Based on the changes of the mass (TG signal), the heating rate is automatically lowered or raised. Generally speaking, the heating rate is reduced during a thermoanalytical event giving a significant signal change [17]. In high-resolution technique the temperature remains almost constant during decomposition, for this reason, decomposition events have more possibilities to be detected and differentiated [13].

TGA can also be used as an indirect method to evaluate the hydration degree of cement paste [20]. This technique is useful to study phenomena associated with formation of hydrated phases of construction materials [13], as well as to determine the evolution of the non-evaporable water content [Wn(t)] and the portlandite content in cement pastes during hydration [20,21]. Parrott et al [22] found a closely but not completely linear correlation between direct measurements (obtained by X-ray diffraction analysis) and nonevaporable water measurement. They determined that this correlation depended on the cement chemical composition.

The degree of hydration is defined as the weight fraction of material reacted. The degree of hydration of a polyphase material, such as Portland cement, requires the determination of the degree of hydration of the individual clinker minerals, but an indirect method will determine some kind of average value for the cement as a whole. The indirect determination of the degree of hydration may be carried out by measuring some property of the product, for example, the amount of chemically combined water, the heat of hydration, the compressive strength or the change in specific volume of the saturated sample, among others [22]. From TGA results it is possible to determine the hydration degree as the ratio between the non-evaporable water amount at time $t$ and the water necessary to reach complete cement hydration [20,21]

In this work the hydration degree was obtained using the model presented by Mounanga et al [20], which is in agreement with the one presented by Zeng et al [21] and can be described according to the equation (1):

$$
\alpha_{T G A}(t)=\frac{W_{n}(t)}{M_{C} * W_{n}(\infty)}(1)
$$

where, $W_{n}(\infty)$ : Corresponds to non-evaporable water mass $(\mathrm{g} / \mathrm{g}$ of cement) to full hydration of $1 \mathrm{~g}$ of cement, which is supposed as $0.2293 \mathrm{~g}$, according to [20] for Portland cements. $W_{n}(t)$ : Represents the non-evaporable water mass $(\mathrm{g})$ at time $\mathrm{t}$, which is obtained from TGA results. $M_{c}$ : Is the measured mass of the sample at the beginning of the test $(\mathrm{g})$.

This work focuses on the use of TGA as a characterization technique to determine phases present and the hydration degree of three different commercial cements during the first day of hydration: a white cement (CEM 1) and two grey cements (CEM 2 and CEM 3). The mineralogical composition of the white one has great differences comparing to the grey cement ones. Grey cements have a similar mineralogical composition, but one of them has a coarser particle size distribution (PSD). The objective is to determine the effect of mineralogical composition and PSD of Portland cements on the hydration degree during the first hours of reaction. 


\section{Experimental procedure}

2.1 Mineralogical composition

Table 1 presents the mineralogical composition for all cements. XRD tests were performed in a PANalytical $X^{\prime}$ Pert PRO MPD, with a $6-70^{\circ}$ (20) range, steps of $0.013^{\circ}$ and accumulation time of 59 s. The quantification of the phases of anhydrous cements was realized using the Rietveld method and the FullProf software.

Table 1 Mineralogical composition of cements obtained by Rietveld method

\begin{tabular}{cccc}
\hline & CEM 1 (\%) & CEM 2 (\%) & CEM 3 (\%) \\
\hline $\mathrm{C}_{3} \mathrm{~S}$ & 59.6 & 64.4 & 63 \\
\hline $\mathrm{C}_{2} \mathrm{~S}$ & 9.8 & 14 & 19.5 \\
\hline $\mathrm{C}_{3} \mathrm{~A}$ & 5.4 & 13.2 & 10.2 \\
\hline $\mathrm{C}_{4} \mathrm{AF}$ & - & 3.1 & 4.6 \\
\hline $\mathrm{Gypsum}_{\mathrm{CaCO}}$ & 10.1 & 2.4 & 2.1 \\
\hline $\mathrm{CaC}_{\mathrm{wp}} / \mathrm{R}_{\mathrm{e}}$ & 15.1 & 2.9 & 0.6 \\
\hline
\end{tabular}

The mineralogical composition shows an addition of $\mathrm{CaCO}_{3}$ in $\mathrm{CEM} 1$ and a low content in $\mathrm{C}_{3} \mathrm{~A}$, compared to CEM 2 and CEM 3. It can also be noticed the similarity of CEM 2 and CEM 3. There is almost no difference on $\mathrm{C}_{3} \mathrm{~S}$, but the main difference is due to the content of $\mathrm{C}_{2} \mathrm{~S}$, which is higher in CEM 3. It is important to realize that the $\mathrm{C}_{2} \mathrm{~S}$ content is not relevant for the hydration time studied in this work (24 hours), because this phase begins to react during the second day of hydration, according to [23].

\subsection{Particle size distribution (PSD)}

Fig. 1 shows the particle size distribution of the cements used. PSD for each cement was obtained using a Mastersizer 2000 of Malvern Instruments.

Fig. 1 PSD of the three cements

Table 2 presents the results for d90, d50 and d10 diameters for the three cements, which corroborates that CEM 2 is the finest of them, while CEM 3 is the coarsest.

Table 2 d90, d50 and d10 for all cements

\begin{tabular}{cccc}
\hline & d90 & d50 & d10 \\
\hline CEM 1 & $43 \mu \mathrm{m}$ & $20 \mu \mathrm{m}$ & $5 \mu \mathrm{m}$ \\
\hline CEM 2 & $35 \mu \mathrm{m}$ & $17 \mu \mathrm{m}$ & $4 \mu \mathrm{m}$ \\
\hline CEM 3 & $51 \mu \mathrm{m}$ & $24 \mu \mathrm{m}$ & $7 \mu \mathrm{m}$ \\
\hline
\end{tabular}

According to Rietveld and PSD results, the main difference of CEM 2 and CEM 3 corresponds to their particle size distribution and the content of $\mathrm{C}_{2} \mathrm{~S}$, which is $14 \%$ for CEM 2 and $19.4 \%$ for CEM 3 .

2.3 Paste preparation 
Pastes were prepared according to ASTM C305 standard [24] using w/c ratio of 0.4 for each cement type to guarantee complete hydration of the pastes. Pastes were cured in $25{ }^{\circ} \mathrm{C}$ water and then the hydration process was arrested with acetone at the hydration ages of 1, 6, 12, and 24 hours. After the arresting process the samples were put in a $60^{\circ} \mathrm{C}$ oven for one hour to eliminate the excess of water.

\subsection{Thermogravimetric Analysis (TGA)}

A TGA 850 Mettler - Toledo equipment was used to develop the TGA tests. It has a horizontal microbalance $(0.1 \mu \mathrm{g}$ resolution), a furnace and temperature sensors connected to a computer to record data.

The material was put into $100 \mu \mathrm{L}$ aluminum crucibles with sealable lid. The lid has a little perforation to create a self-generated atmosphere, the vapor pressure increases into the crucible, the decomposition temperature rises increasing the equilibrium time between the sample and its gaseous phase. It lets the separation of two close processes, according to Borrachero et al [14]. The heating interval was established between 35 and $600{ }^{\circ} \mathrm{C}$, with a heating rate of $10{ }^{\circ} \mathrm{C} / \mathrm{min}$ and no purge gas was used during the tests. For the high resolution tests a heating range between 35 and $300{ }^{\circ} \mathrm{C}$ using a minimum heating rate of $0.5^{\circ} \mathrm{C} / \mathrm{min}$ and a maximum heating rate of $10^{\circ} \mathrm{C} / \mathrm{min}$.

The non-evaporable water content obtained by TGA test was used to determine the hydration degree of the three different cements, using equation (1).

\section{Results and discussion}

\subsection{Effect of hydration time on DTG tests}

Fig. 2 shows DTG curves for all cements at different hydration times. Fig. 2(a) presents the evolution of CEM 1 DTG results from 1 hour till 24 hours of hydration, while Fig. 2(b) and Fig. 2 (c) present the corresponding results for CEM 2 and CEM 3 respectively. For all cements and for all reaction times a unique peak between 500 and $600{ }^{\circ} \mathrm{C}$ was observed. This peak is observed for CEM 1 after 1 hour of hydration. It can be seen that when hydration time increases from 1 hour to 24 hours this peak becomes more intense, which can be corroborated through determination of the percentage presented at each time. According to the literature, this peak corresponds to portlandite decomposition and because it is the only one in this zone of the thermogram then it is possible to determine the quantity of portlandite phase for each hydration time.

In all derivative curves there is another mass loss between 100 and $200{ }^{\circ} \mathrm{C}$. Samples with hydration time of 1 and 6 hours present a peak with a shoulder and another little peak after the first one. The decomposition of ettringite, gypsum and $\mathrm{C}-\mathrm{S}-\mathrm{H}$ takes place in this temperature range.

At the other two ages (12 and 24 hours) the little peak does not appear, but the shoulder of the first peak can be seen. It seems that this peak is wider at these ages. The percentage of water loss in this part of the thermogram for 12-24 hydration hours is greater than those observed at the earlier ages, indicating a significant evolution of hydration process.

It is not possible to determine exactly how many phases are in the $100-200{ }^{\circ} \mathrm{C}$ zone of the thermogram and which phase corresponds to each peak or shoulder of the peak. Because of hydration times, there should be ettringite and possible, at earlier ages, the shoulder or little peak temperature in the range $\left(170-200^{\circ} \mathrm{C}\right)$ could represent the dehydration of gypsum, as reported by Borrachero et al [14]. It is also not possible to quantify the present hydrates, but the amount of water loss can be determined.

Until this point, only portlandite quantity can be calculated for each hydration time.

The following equation is used to calculate portlandite content:

$$
C H=\frac{H}{P M_{H}} \times P M_{C H}
$$

$H$ : Water loss due to portlandite decomposition (in percentage) 
$P M_{H}:$ Water molecular weight

$P M_{C H}$ : Portlandite molecular weight

CH: Portlandite content (in percentage)

Fig. 2 TGA test for all cements at different hydration times. (a) CEM 1; (b) CEM 2; (c) CEM 3. Percentage values correspond to mass loss (\%) associated to each decomposition peak and values on the right of the DTG curves represent the total mass loss in the studied temperature range.

Fig. 3 presents the content of portlandite for all cements at 1, 6, 12 and 24 hours of hydration.

Fig. 3 Evolution of portlandite vs. hydration time for all cements

From the results presented in Fig. 3 and Fig. 2 it can be corroborated that the hydration process of cements is according to the expecting. Portlandite and other hydrates content increases with hydration time during the first hours of hydration.

From Fig. 3, which represents the evolution of portlandite during hydration time for all cements, it can be seen that CEM 2 has the highest portlandite content during the first 12 hours of hydration. From Fig. 2 and Fig. 3 it can be deduced, for each hydration time that CEM 1 has the least content of portlandite, being these values similar to the ones obtained for CEM 3, especially for 6 and 12 hours of hydration. This can be explained according to mineralogical composition. CEM 1 has the lowest content of $\mathrm{C}_{3} \mathrm{~S}(59 \%)$ and does not have any $\mathrm{C}_{4} \mathrm{AF}$, which, according to Mounanga et al [20], also participates in the process of portlandite formation during the first 24 hours of hydration. The portlandite content of CEM 3 is lower than for CEM 2, except at 24 hours of hydration. At this time the portlandite content is the same for CEM 2 and CEM 3. Both cements have a similar content of $\mathrm{C}_{3} \mathrm{~S}$, but CEM 3 has a 5 percentage points less of this phase and also a coarser PSD, which hampers the hydration kinetics, especially during the first hours of hydration.

To obtain water loss associated to other present hydrates, it is necessary to subtract the water content associated to portlandite from the total water loss (in percentage) given by the equipment. In Fig. 2 these values can be read on the right of each curve (e.g.: $4.34 \%$ for 1 hour, for CEM 1). It can be seen from Fig. 2 that CEM 1 has higher content of water associated to other hydrates for all studied ages. Since 6 hours of hydration, these values are similar to the values of CEM 2, showing a synergic effect between fineness and mineralogical composition to control the hydration rate. CEM 3 has the lowest amount of water from other hydrates during the first 24 hours of hydration. At first, this result is unexpected according to the low amount of $\mathrm{C}_{3} \mathrm{~A}$ and $\mathrm{C}_{3} \mathrm{~S}$ of CEM 1 compared to CEM 2 and CEM 3. But it can be explained due to an important addition of $\mathrm{CaCO}_{3}$ in CEM 1 that can accelerate the formation of hydrated products in cement pastes, because it acts as heterogeneous nucleation center between clinker grains, due to its fineness, as it has been explained by Taylor [25] and Nadelman et al [26]. The dehydration peak of gypsum around $180{ }^{\circ} \mathrm{C}$ is found for all cements at one hour of hydration. This peak continues to appear in CEM 1 for 6 hours of hydration. This can be explained according to the higher content of gypsum for this cement, as reported in Table $\mathbf{1}$.

\subsection{High-resolution TGA tests (HRTG)}

In order to improve the resolution of peaks in the $100-200{ }^{\circ} \mathrm{C}$ interval, high-resolution TGA tests were carried out for the same samples in a range of 35 to $300{ }^{\circ} \mathrm{C}$. When a mass change is detected by the equipment, it lowers the heating rate from 10 up to $0.5{ }^{\circ} \mathrm{C} / \mathrm{min}$. The results of high-resolution tests are presented in Fig. 4 for all cements and hydration times.

Fig. 4(a) presents HRTG results for CEM 1, while Fig. 4(b) and Fig. 4(c) show high-resolution TGA tests for CEM 2 and CEM 3, respectively. For all cements it can be seen that peaks between 100 and $200{ }^{\circ} \mathrm{C}$ are well defined. In curves for 1 and 6 hours of hydration time of all cements only one peak is obtained. In all cases this peak is larger for 6 hours of hydration than for 1 hour, indicating an increase of the phase associated to 
that peak. It should correspond to ettringite for all cements, because $\mathrm{C}_{3} \mathrm{~A}$ is the first anhydrous phase to react in presence of water and gypsum. Although the content of gypsum is very low for CEM 2 and CEM 3, they can produce ettringite, but its quantity should be lower than for CEM 1 . This can be corroborated with values from Fig. 2, where the amount of water total mass loss is greater for CEM 1 than for the other two cements.

For 12 hours of hydration of CEM 1, according to Fig. 4 (a), three peaks are detected. One peak appears at the same temperature that the peak observed for 1 and 6 hours of hydration, on each side of this peak there are both smaller peaks. The greater peak in the middle corresponds to decomposition of ettringite, while the other two correspond to decomposition of C-S-H as reported by Tobon et al [13]. For CEM 2 (Fig. 4(b)) at 12 hours, it can be noticed the same peak obtained for 1 and 6 hours of hydration (ettringite decomposition) and another peak on the left of the first one. The first peak is larger than at 1 and 6 hours, because of its high content of aluminate phases $\left(13.2 \%\right.$ of $\mathrm{C}_{3} \mathrm{~A}$ and $3.1 \%$ of $\left.\mathrm{C}_{4} \mathrm{AF}\right)$. The other peak should correspond to C-S-H decomposition. CEM 2 has a great amount of $\mathrm{C}_{3} \mathrm{~S}$, which starts to react during the first hours of hydration and being the finer cement of this work, which facilitates the hydration process. For CEM 3 at 12 hours only one peak is detected using the high-resolution module. This peak is greater at this age than at the other former ages. The mineralogical composition of this cement is similar to CEM 2, but it is not as fine as CEM 2, which may hamper the hydration process.

At 24 hours of hydration for CEM 1 and CEM 2 as it can be seen in Fig. 4(a) and Fig. 4(b) respectively, the same peaks of 12 hours appear at this age. Peaks are larger at 24 hours than at 12 hours. For CEM 3 at 24 hours of hydration (Fig. 4(c)) a new little peak appears. As reported by Tobon et al [13] and according to the mineralogical composition presented in Table 1, this little peak corresponds to decomposition of C-S-H. The C-S-H peak at the left of ettringite could have not appeared, because high resolution TGA has not detected an enough lost rate to determine this peak, as there is few C-S-H for the cement with the coarsest particle size distribution.

Fig. 4 High-resolution TGA curves for all cements. (a) CEM 1; (b) CEM 2; (c) CEM 3

\subsection{Hydration degree}

It is possible to determine the hydration degree of a cement paste using the results obtained by TGA. Fig. 5 shows the relationship between time of hydration and hydration degree for all cements. According to the mineralogical composition of CEM1, particularly the percentage of $\mathrm{C}_{3} \mathrm{~A}$ and $\mathrm{C}_{3} \mathrm{~S}$ that govern hydration process during the first 24 hours, it was expected that the hydration degree of this cement may be lower than for the other cements: however contrary of obtained results were observed. It can be explained because of the quantity of $\mathrm{CaCO}_{3}$. When calcite is present as fine particles, the hydration reaction of cement is accelerated. Using a sieving process, it was corroborated that calcite in CEM 1 has a fine size. Only a little quantity of calcite was retained in the 325 sieve, while almost all passed through a 400 sieve, as it was determined by Rietveld quantification. As can be seen in Fig. 5, CEM 1 has a higher hydration degree for each hydration time studied, while CEM 3 has the lowest hydration degree for each time. At 24 hours of hydration CEM 1 has a hydration degree of $54 \%$, CEM 2 of $50 \%$ and CEM 3 of $38 \%$. It is important to notice that during the first day, cement paste reach a significant hydration degree, which is responsible for lot of properties of the cement-based materials.

Fig. 5 Hydration degree for three cements

According to mineralogical composition of CEM 2 and CEM 3, it can be concluded that both cements have similar mineralogical composition, but they have a significant difference in PSD. CEM 2 has a little more content of $\mathrm{C}_{3} \mathrm{~A}$ and $\mathrm{C}_{3} \mathrm{~S}$ than $\mathrm{CEM} 3$, which in contrast has more $\mathrm{C}_{4} \mathrm{AF}$ that has also an important influence on hydration during the first day. CEM 2 is finer than CEM 3, meaning that particles in CEM 3 require a longer time to be hydrated than particles in CEM 1 or CEM 2, as reported by Taylor [25].

Taking into account only the PSD of cements, CEM 1 should have lower degree of hydration than CEM 2, because the former has a PSD coarser than the later. According to mineralogical composition, CEM 1 has the 
lowest value of $\mathrm{C}_{3} \mathrm{~A}$ and $\mathrm{C}_{3} \mathrm{~S}$, which are the anhydrous phases governing the cement hydration during the first hours. But CEM 1 has the highest content of $\mathrm{CaCO}_{3}$. As it was stated before, $\mathrm{CaCO}_{3}$ acts as a site for heterogeneous nucleation, because of its fineness, incrementing hydration rate, and therefore, hydration degree. This is corroborated with TGA and hydration degree results.

The fineness of CEM 2 accelerates the hydration process, increasing the hydration degree for the same curing time and the content hydrated phases especially for early ages. According to the results obtained it is clear that hydration degree does not only depend on mineralogical composition, but also on PSD. This increases the work results from Mounanga et al [20], which realized that hydration degree is affected by curing temperature and $\mathrm{w} / \mathrm{c}$ ratio for the same cement type.

Conclusions

- Thermogravimetric analysis is a useful technique to characterize cementitious materials during the first day of hydration.

- High-resolution TGA technique allows separating the overlapping decomposition steps. According to the mineralogical composition of cementitious material, it is possible to predict which phases are decomposed in a temperature interval, where several decomposition reactions may take place.

- It can be noticed that the hydration process is affected by the particle size distribution. When cement is composed by coarser grain size, the hydration process takes a longer time, as was corroborated by TGA results and hydration degree calculation, particularly during the first 12 hours of hydration.

- Addition of calcite as a fine filler has a great influence on the hydration process of Portland cements. It increases the hydration process, since the beginning of the reaction between water and cement.

- According to high-resolution TGA results it was demonstrated that ettringite was the only decomposed phase in the $100-200{ }^{\circ} \mathrm{C}$ interval during the first 6 hours of hydration for all studied cements.

- In general, the C-S-H phase starts to appear in the hydrated cements after 12 hours of hydration.

\section{References}

[1] Benboudjema, F, Meftah J.M, Torernti, F. Interaction between drying, shrinkage, creep and cracking phenomena in concrete. Eng Struct. 2005;27:239-250.

[2] Holt, E. Contribution of mixture design to chemical and autogenous shrinkage of concrete at early ages. Cement Concrete Res. 2005;35:464-472.

[3] Darquennes, A, Staquet, S, Delplancke-Ogletree, M.P,Espion, B. Effect of autogenous deformation on the cracking risk of slag cement concretes. Cement Concrete Comp. 2011;33:368-379.

[4] Slowik, V; Schmidt, M; Fritzsch, R. Capillary pressure in fresh cement-based materials and identification of the air entry value. Cement Concrete Comp. 2008;30(7):557-565.

[5] Evju, C. and Hansen, S. Expansive properties of ettringite in a mixture of calcium aluminate cement, Portland cement and B-calcium sulfate hemihydrates. Cement Concrete Res. 2001;31:257-261.

[6] Bentz, D.P; Jensen, O.M; Hansen, K.K; Olesen, Stang, H. Haecker, C.J. Influence of cement particle-size distribution on early age autogenous strain and stresses in cement-based materials. J Am Ceram Soc. 2001;84(1):129-135.

[7] Barcelo, L., Moranville, M., Clavaud, B. Autogenous shrinkage of concrete: a balance between autogenous swelling and self-desiccation. Cement Concrete Res. 2005;35(1): 177-183. 
[8] Bouasker, M., Mounanga, P., Turcry, P., Loukili, A, Khelidj, A. Chemical shrinkage of cement pastes and mortars at very early age: Effect of limestone filler and granular inclusions. Cement Concrete Comp, 2008;30(1): 13-22.

[9] Bentz, D. P. A review of early-age properties of cement-based materials. Cement Concrete Res. (2008);38(2):196-204.

[10] Ozawa, T. Controlled rate thermogravimetry. New usefulness of controlled rate thermogravimetry revealed by decomposition of polyimide. J Therm Anal Calorim. 2000;59:375-384.

[11] Ramachandran V.S, Paroli R.M, Beaudoin JJ, Delgado AH.Thermal analysis of construction materials. Building materials series. New York: Noyes Publications; 2003.

[12] Zanier, A. High-resolution tg for the characterization of diesel fuel additives. J Therm Anal Calorim. 2001;64:377-384.

[13] Tobón, J.I, Payá, J, Borrachero, M.V, Restrepo, O.J. Mineralogical evolution of Portland cement blended with silica nanoparticles and its effect on mechanical strength. Constr Build Mater. 2012;36: 736-742.

[14] Borrachero, M.V. Payá, J. Bonilla, M. and Monzó, J. The use of thermogravimetric analysis technique for the characterization of construction materials. The gypsum case. J Therm Anal Calorim. 2008;91(2):503509.

[15] Tobón, J.I, Payá, J, Borrachero, M.V, Soriano, L, Restrepo, O.J. Determination of the optimum parameters in the high resolution thermogravimetric analysis (HRTG) for cementitious materials. J Therm Anal Calorim. 2012;107:233-239.

[16] Esteves, P.L. On the hydration of water-entrained cement-silica systems: Combined SEM, XRD and thermal analysis in cement pastes. Thermochim Acta. 2011;518:27-35.

[17] Riesen R. Adjustment of heating rate for maximum resolution in TG and TMA (MaxRes). J Therm Anal. 1998;53:365-374.

[18] Lim, S and Mondal, P. Micro- and nano-scale characterization to study the thermal degradation of cement-based materials. Mater Charact. 2014;92:15-25.

[19] Gill, P.S, Sauerbrunn S. R, and Crowe, B. S. High resolution thermogravimetry. J Therm Anal. 1992;38:255-266.

[20] Mounanga, P, Khelidj, A, Loukili, A, Baroghel-Bouny, V. Predicting $\mathrm{Ca}(\mathrm{OH})_{2}$ content and chemical shrinkage of hydrating cement pastes using analytical approach. Cement Concrete Res. 2004;34:255-265.

[21] Zeng, Q; Li, K; Fen-chong, T; Dangla, P. Determination of cement hydration and pozzolanic reaction extents for fly-ash cement pastes. Constr Build Mater. 2012;27:560-569.

[22] Parrott, L.P, Geiker, M, Gutteridge, W.A and Killoh, D. Monitoring Portland cement hydration: Comparison of methods. Cement Concrete Res. 1990;20:919-926.

[23] Hewlett P.C. Lea's Chemistry of Cement and Concrete. 4th ed. Elsevier Science \& Technology Books, $\mathrm{UK} ; 2004$. 
[24] ASTM C305 Standard practice for mechanical mixing of hydraulic cement pastes and mortars of plastic consistency. ASTM International, West Conshohocken, PA; 2012.

[25] Taylor, H.F. Cement Chemistry. 2nd Edition. UK: Thomas Telford; 1997.

[26] Nadelman, E.I, Freas, D.J and Kurtis, K.E. Nano- and microstructural characterization of Portland limestone cement paste. Nanotechnology in construction. Proceedings of NICOM 5. 2015;87-92. 


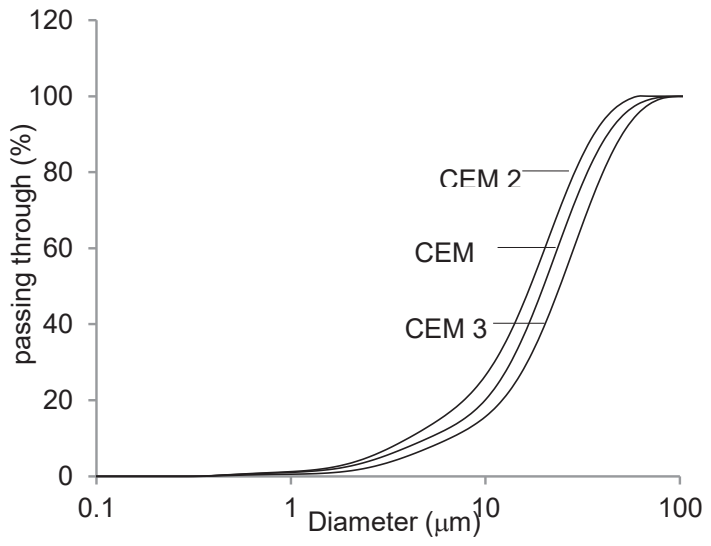

Fig. 1 PSD of the three cements (created in Excel)

(a)

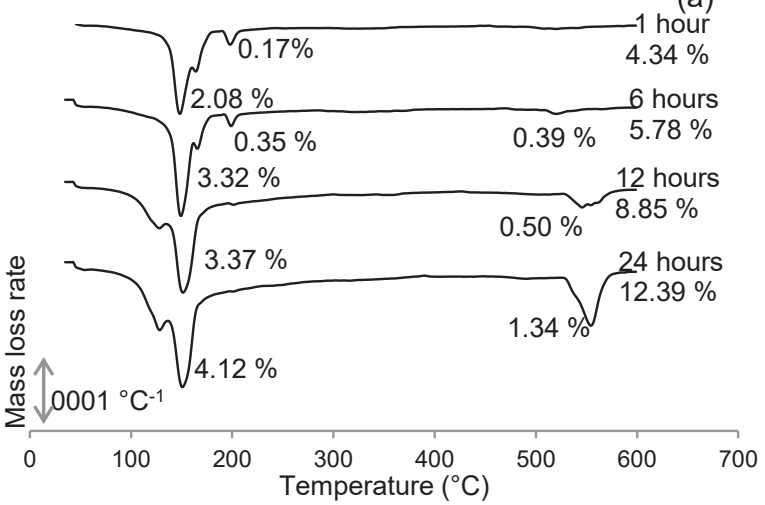

(b)

1 hour

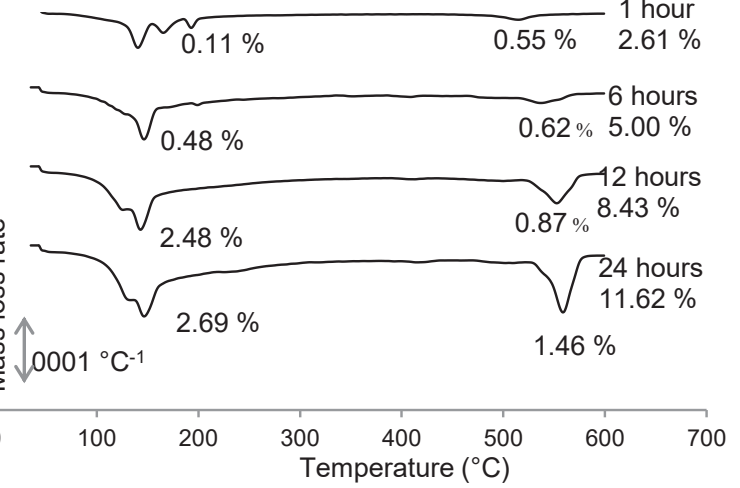




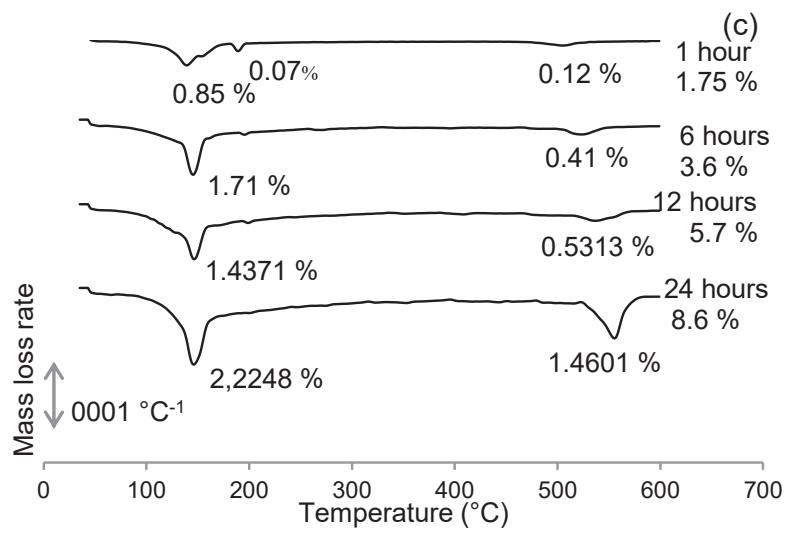

Fig. 2 TGA test for all cements at different hydration times. (a) CEM 1; (b) CEM 2; (c) CEM 3. Percentage values correspond to mass loss (\%) associated to each decomposition peak and values on the right of the DTG curves represent the total mass loss in the studied temperature range (created in Excel).

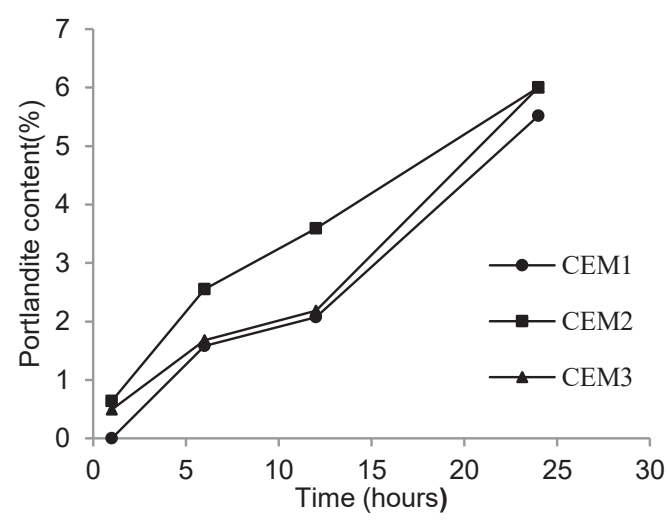

Fig. 3 Evolution of portlandite vs. hydration time for all cements (created in Excel)

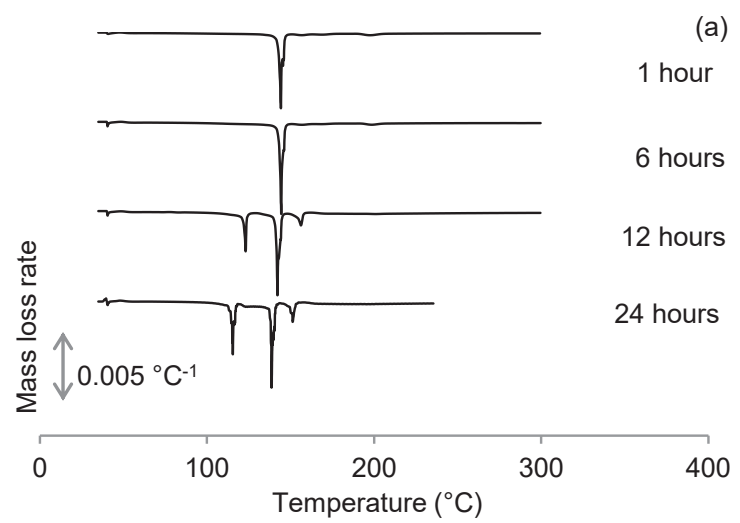


(b)

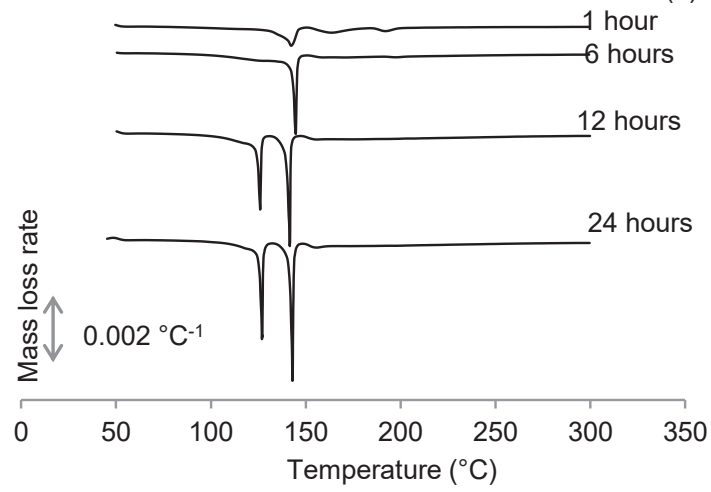

(c)

1 hour

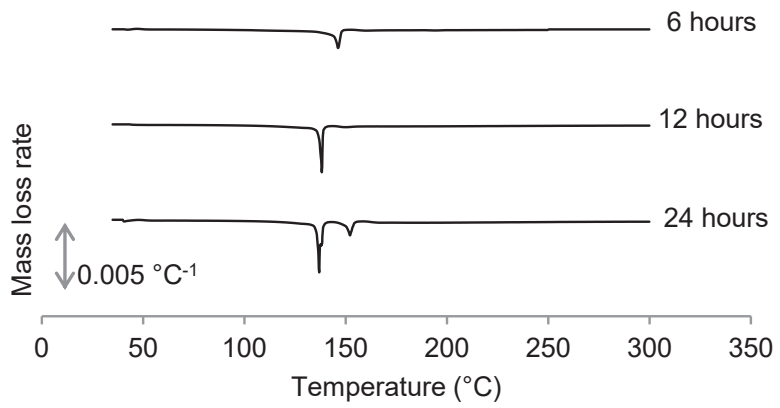

Fig. 4 High-resolution TGA curves for all cements. (a) CEM 1; (b) CEM 2; (c) CEM 3 (created in Excel)

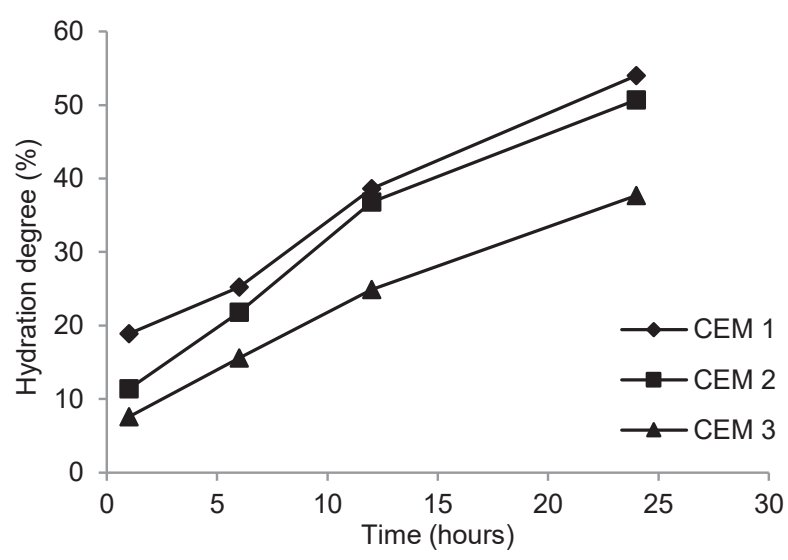

Fig. 5 Hydration degree for three cements (created in Excel) 
Table 1 Mineralogical composition of cements obtained by Rietveld method

\begin{tabular}{cccc}
\hline & CEM 1 (\%) & CEM 2 (\%) & CEM 3 (\%) \\
\hline $\mathrm{C}_{3} \mathrm{~S}$ & 59.6 & 64.4 & 63 \\
\hline $\mathrm{C}_{2} \mathrm{~S}$ & 9.8 & 14 & 19.5 \\
\hline $\mathrm{C}_{3} \mathrm{~A}$ & 5.4 & 13.2 & 10.2 \\
\hline $\mathrm{C}_{4} \mathrm{AF}$ & - & 3.1 & 4.6 \\
\hline $\mathrm{Gypsum}_{\mathrm{CaCO}}$ & 10.1 & 2.4 & 2.1 \\
\hline $\mathrm{CaCO}_{3}$ & 15.1 & 2.9 & 0.6 \\
\hline $\mathrm{R}_{\mathrm{wp}} / \mathrm{R}_{\mathrm{e}}$ & 2.82 & 2.26 & 2.6 \\
\hline
\end{tabular}

Table $2 \mathrm{~d} 90, \mathrm{~d} 50$ and $\mathrm{d} 10$ for all cements

\begin{tabular}{cccc}
\hline & d90 & d50 & d10 \\
\hline CEM 1 & $43 \mu \mathrm{m}$ & $20 \mu \mathrm{m}$ & $5 \mu \mathrm{m}$ \\
\hline CEM 2 & $35 \mu \mathrm{m}$ & $17 \mu \mathrm{m}$ & $4 \mu \mathrm{m}$ \\
\hline CEM 3 & $51 \mu \mathrm{m}$ & $24 \mu \mathrm{m}$ & $7 \mu \mathrm{m}$ \\
\hline
\end{tabular}




\begin{tabular}{|c|c|}
\hline $\begin{array}{l}\text { Author name: Ximena Gaviria } \\
\text { Address: Calle } 164 \text { A3 B } 126 \text { Medellín- } \\
\text { Colombia } \\
\text { E-mail Xgavisiaeudem.edu.co }\end{array}$ & $\begin{array}{l}\text { Publisher: } \\
\text { Akadémiai Kiadó Zrt. } \\
\text { Prielle Kornélia u. 21-35, H-1117 Budapest, Hungary }\end{array}$ \\
\hline $\begin{array}{l}\text { Article title: MINERALOGICAL EVOWUTON } \\
\text { BASED ON THRMOGRAVIMETE } \\
\text { Journal title: JOURNAL OF THERMAL ANAL } \\
\text { Co-Authors: BORRACHERO,M.V; PEÝa, J; M }\end{array}$ & $\begin{array}{l}\text { IF CEMENT DASTES AT EARLY AGES } \\
\text { C AWALYSIS (TGA) } \\
\text { IS ANT CALORIMETRY } \\
\text { nZEJJ.M; TObÖn, J.I }\end{array}$ \\
\hline
\end{tabular}

\section{Statements of the Author}

I undersigned Author assume the liability by signing the present agreement to provide the above article to the Publisher and authorize the Publisher to issue the above indicated article in the above indicated journal. I acknowledge that the Publisher shall be entitled to the publishing and copyrights of the article and shall be licensed to use the article under the terms and conditions included in the present statement after the first publication.

I grant to Akadémiai Kiadó Zrt. an irrevocable exclusive license to publish the article in electronic and print format, and further sublicense the article in its original language throughout the world.

\section{The Publisher's license for use}

The Publisher shall be entitled to the exclusive publishing and copyrights of the article and shall be licensed to use the article according to the statement under the above section 1. without any geographical or time limitation, including, without any geographic, lingual, time, copy or any other limitation, the right of storage of the article, its recording on a computer or on any electronic data medium, the right to print, publish, copy, distribute and sell the article in optional form of printing, and on any on-line and off-line data medium.

\section{Warranties and other commitments of the Author}

The Author shall declare and warrant that

- he/she is the exclusive author of the article along with the above indicated co-authors and he/she has the approval of all the other co-authors to publish the article in its current form,

- the article is their own intellectual product,

- the article is original, has not been formally published in any other peer-reviewed journal, is not under consideration by any other journal and does not infringe any existing copyright or any other third party rights

- there is no plagiarism in the article, the content is punctual and true to the best of the Author's knowledge, it does not include any libel, or parts that are obscene or violate the copyrights, private life or any other rights of a third party, or that are illegal and shall warrant that the manuscript is not partly or entirely under review or being published at any other journals either in English or in any other languages.

- the Author shall accept that he/she shall provide the exact location of the first publication of the article when making the article available to any third party and shall enclose the link to the location of the first publication in the following format: (https://doi.org/[The DOI-number of the article without brackets]).

\section{Green Open Access / Self archiving}

Akadémiai Kiadó is a Green Publisher, so our Authors are entitled to self-archive the preprint version of their manuscript. The preprint version is the Author's manuscript or the galley proof or the Author's manuscript along with the corrections made in the course of the peer review process. The Author's right to self-archive is irrespective of the format of the preprint (.doc, .tex, .pdf, etc.) version and self-archiving includes the free circulation of this file via e-mail or publication of this preprint on the Author's webpage or on the Author's institutional repository with open or restricted access or any repository mandated by Author's funding body. When self-archiving a paper the Author should clearly declare that the archived file is not the final published version of the paper, he/she should quote the correct citation and enclose a link to the published paper (https://doi.org/[DOl of the Article without brackets]).

In case the aforementioned link is not enclosed even following the Publisher's notice or Author violates the above access restrictions, Publisher is entitled to claim the valid Open Access fee to be paid by Author.

Date: 25.01 .20 .7

Author's Signature: Xumendqaviria 
http://www.springer.com/journal/10973

Journal of Thermal Analysis and Calorimetry An International Forum for Thermal Studies

Editor-in-Chief: Kállay-Menyhárd, A.

ISSN: $1388-6150$ (print version)

ISSN: 1588-2926 (electronic version)

Journal no. 10973 